\title{
On accounting for tempering effect in unsteady creep model for metals
}

\author{
Ivan Volkov ${ }^{1}$, Leonid Igumnov ${ }^{1, *}$, Aleksandr Ryabov ${ }^{1}$, and Denis Shishulin ${ }^{1}$ \\ ${ }^{1}$ National Research Lobachevsky State University of Nizhni Novgorod, Research Institute for Mechanics, 603950 Nizhny Novgorod, \\ Russian Federation
}

\begin{abstract}
A mathematical model describing processes of nonstationary creep of metals under multiaxial stress state is developed. A phenomenon of reverse creep modeling is considered in more details. The results of numerical modeling of the reverse creep process in variety of structural steels are presented. Obtained numerical results are compared with available results of physical experiments.
\end{abstract}

\section{Introduction}

The study of the laws of inelastic deformation of structural materials under uniaxial and multiaxial stressed state is important for the development of the fundamentals of the mathematical theory of creep. With a considerable number of experimental studies of the creep process of structural alloys [1], experiments on the study of the phenomenon of reverse creep (the phenomenon of decreasing deformations in time after removing the load) of metals is comparatively small. As a result, this effect is not taken into account in most cases during the calculation of structural elements creep nowadays.

At the same time, in order to verify the physical reliability of the defining equations of the creep theory, calculations and comparison of the obtained numerical results with the data available in the literature on a wide range of experiments are required [2-16]. The results of such researches can also be useful in determining (specifying) the material parameters of the scalar functions and functionals involved in defining equations of nonstationary creep. Moreover, fast unloading of elements and components of load-bearing structures can lead to stress loading of the opposite sign, which in some cases is unacceptable (deformation of reverse creep is commensurable with elastic deformation).

A mathematical model of the nonstationary creep of metals under a multiaxial stressed state was developed in [17-19]. In [19], reliability estimation was carried out and the boundaries of applicability of the developed defining relations of nonstationary creep under multiaxial stress state were determined. Applicability boundaries of the developed defining relations of nonstationary creep under multiaxial stress state were determined as well as reliability estimation was done in [19].

This model is modified to describe the phenomenon of inverse creep and an estimate of its reliability by comparing the obtained numerical results with the experimental data available in the literature on the inverse creep of structural steels is given in this paper.

\section{The defining relations of nonstationary creep}

General considerations of the nonstationary creep equations [17-19] are:

- Initially isotropic media are considered.

- The strain and strain rates tensors are sums of the "instantaneous" and " time-dependent" components. The "instantaneous" component consists of elastic strains that do not depend on the loading history and determined by the final state of the process, and plastic strains depending on the loading history. The time component (creep strains) describes the time dependence of deformation processes at low loading speeds.

- The equipotential surface evolution is determined by changes in its radius $C_{c}$ and displacements of its centre $\rho_{i j}^{c}$.

- The change in the body volume is determined only by the elastic strains: $e_{i i}^{p}=e_{i i}^{c}=0$.

- Deformation processes characterized by small strains are considered.

The strain and strain rate tensors $e_{i j}$ and $\dot{e}_{i j}$ are sums of the elastic strains $e_{i j}^{e}, \dot{e}_{i j}^{\prime e}$, plastic strains $e_{i j}^{p}, \dot{e}_{i j}^{\prime p}$ and creep strains $e_{i j}^{c}, e_{i j}^{\prime c}$, i.e.:

$$
e_{i j}=e_{i j}^{e}+e_{i j}^{p}+e_{i j}^{c} ; \dot{e}_{i j}=\dot{e}_{i j}^{e}+\dot{e}_{i j}^{p}+\dot{e}_{i j}^{c}, i, j=1,2,3 .
$$

The relationship between the stress tensor and elastic strain tensor is based on thermoelasticity equations:

$$
\sigma=3 K[e-\alpha T)] ; \dot{\sigma}=3 K[\dot{e}-\dot{\alpha} T-\alpha \dot{T})]+\frac{\dot{K}}{K} \sigma
$$

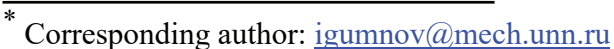




$$
\sigma_{i j}^{\prime}=2 G e_{i j}^{\prime e}, \dot{\sigma}_{i j}=2 G \dot{e}_{i j}^{\prime e}+\frac{\dot{G}}{G} \sigma_{i j}^{\prime}, e_{i j}^{\prime e}=e_{i j}^{\prime}-e_{i j}^{c}
$$

where $\sigma, e$ are spherical and $\sigma_{i j}^{\prime}, e_{i j}^{\prime}$ are deviatoric components of the corresponding stress $\sigma_{i j}$ and strain $e_{i j}$ tensors; $G(T)$ is the shear modulus, $K(T)$ is the volumetric compression modulus, $\alpha(T)$ is the coefficient of linear temperature expansion of the material.

To describe the creep processes, we introduce in the stress space the equipotential creep surfaces $F_{c}$ having the same centre $\rho_{i j}^{c}$ and different radii $C_{c}$, determined by the current state of stress:

$$
F_{c}^{(i)}=S_{i j}^{c} S_{i j}^{c}-C_{c}^{2}=0, S_{i j}^{c}=\sigma_{i j}^{\prime}-\rho_{i j}^{c}, i=0,1,2, \ldots
$$

In accordance with the associativity law

$$
\dot{e}_{i j}^{c}=\lambda_{c} \frac{\partial F_{c}^{(i)}}{\partial S_{i j}^{c}}=\lambda_{c} S_{i j}^{c},
$$

where $\lambda_{c}$ corresponds to the current surface $F_{c}^{(i)}$, defining current stress state $S_{i j}^{c}$.

The surface with radius $\bar{C}_{c}$ may be outlined among these equipotential surfaces as corresponding to zero creep rate:

$$
F_{c}^{(0)}=\bar{S}_{i j}^{c} \bar{S}_{i j}^{c}-\bar{C}_{c}^{2}=0, \bar{S}_{i j}^{c}=\bar{\sigma}_{i j}^{\prime}-\rho_{i j}^{c},
$$

where $\bar{S}_{i j}^{c}$ and $\bar{\sigma}_{i j}^{\prime}$ are set of strained states that correspond (with a certain tolerance) to the zero creep rate.

Consider that

$$
\begin{gathered}
\bar{C}_{c}=\bar{C}_{c}\left(\chi_{c}, T\right) ; \dot{\chi}_{c}=\left(\frac{2}{3} \dot{e}_{i j}^{c}, \dot{e}_{i j}^{c}\right)^{1 / 2} ; \chi^{c}=\int_{o}^{t} \dot{\chi}^{c} d t, \\
\lambda_{c}=\lambda_{c}\left(\psi_{c}, T\right) ; \psi_{c}=\left[\frac{\left(S_{i j}^{c} S_{i j}^{c}\right)^{1 / 2}-\bar{C}_{c}}{C_{c}}\right],
\end{gathered}
$$

where $\bar{C}_{c}$ and $\lambda_{c}$ are experimentally determined functions of temperature $\mathrm{T}$.

The evolution equation for the coordinates of the centre of the creep surface has the following form [17-19]:

$$
\dot{\rho}_{i j}^{c}=g_{1}^{c} \dot{e}_{i j}^{c}-g_{2}^{c} \rho_{i j}^{c} \dot{\chi}_{c},
$$

where $g_{1}^{c}$ and $g_{2}^{c}>0$ are experimentally determined material parameters.

By specifying (3) the law of gradientality can be represented as

$$
\dot{e}_{i j}^{c}=\lambda_{c}\left(\psi_{c}, T\right) S_{i j}^{c}=\lambda_{c} \psi_{c} S_{i j}^{c}=S_{i j}^{c} \lambda_{c}\left(\frac{\sqrt{S_{i j}^{c} S_{i j}^{c}}-\bar{C}_{c}}{C_{c}}\right) .
$$

The intensity of the creep strain rate tensor has the following form:

$$
\dot{e}_{u}^{c}=\lambda_{c}\left(\frac{\sqrt{S_{i j}^{c} S_{i j}^{c}}-\bar{C}_{c}}{C_{c}}\right) S_{u}^{c} .
$$

By taking into account (8) we are getting the following expression for the length of the creep strain path:

$$
\dot{\chi}_{c}=\sqrt{\frac{2}{3}} \dot{e}_{u}^{c}=\sqrt{\frac{2}{3}} \lambda_{c}\left(\sqrt{S_{i j}^{c} S_{i j}^{c}}-\bar{C}_{c}\right)
$$

and

$$
\lambda_{c}=\frac{\dot{\chi}_{c}}{\sqrt{\frac{2}{3}}\left(\sqrt{S_{i j}^{c} S_{i j}^{c}}-\bar{C}_{c}\right)} .
$$

The dependence of $\chi_{c}$ on the time $t$ with $S_{u}^{c}=$ const in the case of multi-axis straining over the ray trajectory is shown in Fig. 1.

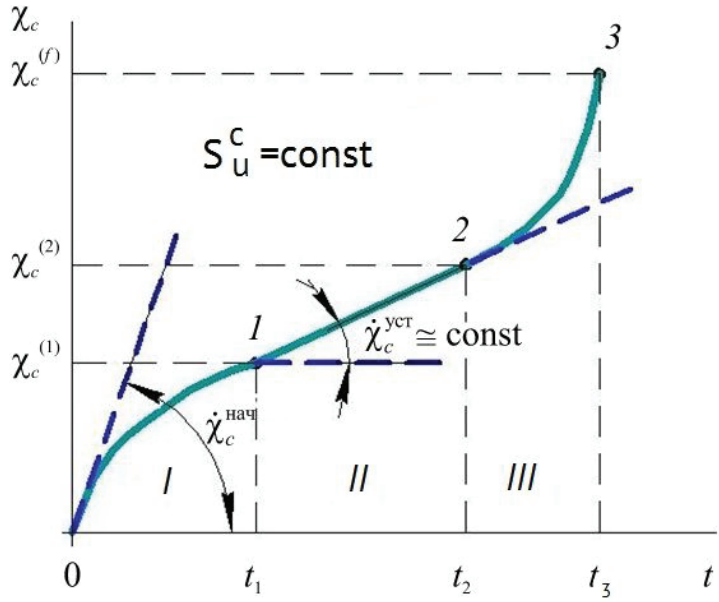

Fig. 1. The dependence of $\chi_{c}$ on the time $t$ in case of multi-axis straining.

The curve $\chi_{c} \sim t$ (Fig. 1) can be conventionally divided into three segments:

I. segment of unsteady creep $\left(0-\chi_{c}^{(1)}\right)$ where the creep-induced strain rate $\dot{\chi}_{c}$ decreases.

II. segment of steady creep $\left(\chi_{c}^{(1)}-\chi_{c}^{(2)}\right)$ where the creep-induced strain rate is approximately constant $\dot{\chi}_{c} \cong$ const .

III. segment of unsteady creep $\left(\chi_{c}>\chi_{c}^{(2)}\right)$ where the creep-induced strain rate $\dot{\chi}_{c}$ drastically increases (followed by fracture).

The lengths of these segments depend on the value of $S_{u}^{c}=$ const . have

In the case of uniaxial stress state of the specimen we 


$$
\begin{gathered}
\dot{\chi}_{c}=\dot{e}_{11}^{c}, \bar{C}_{c}=\sqrt{\frac{2}{3}} \bar{\sigma}_{c} \\
\left(\sqrt{S_{i j}^{c} S_{i j}^{c}}-\bar{C}_{c}\right)=\sqrt{\frac{2}{3}}\left(\sigma_{11}^{\prime}-\frac{3}{2} \rho_{11}^{c}-\bar{\sigma}_{c}\right) ; \\
\dot{e}_{11}^{c}=\frac{2}{3} \lambda_{c}\left(\sigma_{11}^{\prime}-\frac{3}{2} \rho_{11}^{c}-\bar{\sigma}_{c}\right) ; \\
\dot{\chi}_{c}=\dot{e}_{11}^{c} \chi_{c}^{(1)}=e_{11}^{c(1)} ; \chi_{c}^{(2)}=e_{11}^{c(2)} ; \chi_{c}^{(3)}=e_{11}^{c(3)},
\end{gathered}
$$

where $\bar{\sigma}_{c}=\bar{\sigma}_{c}\left(e_{11}^{c}, T\right)$ is the creep limit of the material corresponding to zero creep rate. In this case the diagram $\chi_{c} \sim t$ is equivalent to the diagram $e_{11}^{c} \sim t . \lambda_{c}$ may be obtained using (13) on the second segment $\left(e_{11}^{c(1)} \leq e_{11}^{c} \leq e_{11}^{c(2)}\right)$ :

$$
\lambda_{c}^{I I}=\frac{3}{2} \frac{\dot{e}_{11}^{f a t}}{\left(\sigma_{11}^{\prime}-\frac{3}{2} \rho_{11}^{c}-\bar{\sigma}_{c}\right)} .
$$

On the segment $\left(0 \leq e_{11}^{c} \leq e_{11}^{c(1)}\right)$

$$
\dot{e}_{11}^{c}=\left\{\begin{array}{l}
\dot{e}_{11}^{c(\text { init })}, \text { when } e_{11}^{c}=0, \\
\dot{e}_{11}^{c(f a t)}, \text { when } e_{11}^{c}=e_{11}^{c(1)} .
\end{array} .\right.
$$

Taking into account these equations we may represent $\lambda_{c}^{I}$ on the first segment of creep curve as:

$$
\lambda_{c}^{I}=\lambda_{c}^{(0)}\left(1-\frac{e_{11}^{c}}{e_{11}^{c(1)}}\right)+\lambda_{c}^{(1)} \frac{e_{11}^{c}}{e_{11}^{c(1)}}
$$

where

$$
\lambda_{c}^{(0)}=\frac{3}{2} \frac{\dot{e}_{11}^{c(\text { init })}}{\left(\sigma_{11}^{\prime}-\bar{\sigma}_{c}\right)}, \lambda_{c}^{(1)}=\frac{3}{2} \frac{\dot{e}_{11}^{c(f a t)}}{\left(\sigma_{11}^{\prime}-\frac{3}{2} \rho_{11}^{c}-\bar{\sigma}_{c}\right)}
$$

are the values of $\lambda_{c}$ in points " 0 " and " 1 ", respectively.

On third segment $\left(e_{11}^{c(2)}<e_{11}^{c} \leq e_{11}^{c(3)}\right)$ prior to fracture:

$$
\lambda_{c}^{I I I}=\lambda_{c}^{I I} /(1-\omega)^{r_{c}}
$$

where $\omega$ is a measure of damage and $r_{c}$ is a material parameter [17].

Extending the resultant relations to the non-one-dimensional case, we obtain:

$$
\lambda_{c}=\left\{\begin{array}{l}
\lambda_{c}^{I}, 0 \leq \chi_{c} \leq \chi_{c}^{(1)} \\
\lambda_{c}^{I I}, \chi_{c}^{(1)} \leq \chi_{c} \leq \chi_{c}^{(2)}, \\
\lambda_{c}^{I I I}, \chi_{c}^{(2)} \leq \chi_{c} \leq \chi_{c}^{(3)}
\end{array},\right.
$$

Equations (1)-(18) describe unsteady and steady-state segments of the creep curve at different stress levels and the main effects of the creep process under alternating stress.

To describe the phenomenon of inverse creep, the law of gradientality can be represented in the form:

$$
\dot{e}_{i j}^{c}=\left\{\begin{array}{l}
\lambda_{c}^{(+)}\left(\sqrt{S_{i j}^{c} S_{i j}^{c}}-\bar{C}_{c}^{(+)}\right) n_{i j}^{c}, \sqrt{S_{i j}^{c} S_{i j}^{c}}>\bar{C}_{c}^{(+)} \\
0, \quad \vdots \quad \bar{C}_{c}^{(-)} \leq \sqrt{S_{i j}^{c} S_{i j}^{c}}<\bar{C}_{c}^{(+)}, \\
\lambda_{c}^{(-)}\left(\sqrt{S_{i j}^{c} S_{i j}^{c}}-\bar{C}_{c}^{(-)}\right) n_{i j}^{c}, \sqrt{S_{i j}^{c} S_{i j}^{c}}<\bar{C}_{c}^{(-)}
\end{array}\right.
$$

where $n_{i j}^{c}=S_{i j}^{c} / \sqrt{S_{i j}^{c} S_{i j}^{c}}, \quad \lambda_{c}^{(+)}$obtained using equation (19) and $\lambda_{c}^{(-)}=$const determined from the reverse creep experiments.

It is always a compromise between the correspondence of the model to the actual behaviour of the material under operational conditions, the possibility and efficiency of the model in solving applied problems on a computer, the possibility of experimentally determining the material parameters of the model and the accuracy of these parameters. It is necessary to find this compromise while developing models of deformation and fracture of materials for a wide range of thermomechanical loads with a wide range of applicability. In case it is not possible to accurately determine the material parameters the model can be useless in practice [17]. That is the reason why this variant of the defining relations of nonstationary thermal creep under the complex stress state (1)-(18) was formulated as a system of "nested" models.

In the absence of the required experimental data or due to the unimportant effect of these or other physical effects, the particular relationships of unsteady creep under a complex stress state may be obtained by omitting corresponding material parameters.

\section{Results of numerical calculations}

The results of experimental studies of reverse creep conducted by McWethie and Waugh on a number of structural steels are presented in [20]. In the first example, we calculated a creep of a specimen made of steel with content of $0,35 \% \quad \mathrm{C}$ (steel 35) at the temperature $T=450^{\circ} \mathrm{C}$ and stress $\sigma_{11}=52 \mathrm{MPa}$ within $t=9070 \mathrm{~h}$. In this case a value of strain is $e_{11}=0,587 \%$. After that the specimen was quickly unloaded to the value $\sigma_{11}=7,7 \mathrm{MPa}$, elastic strain decreased to $e_{11}=0,029 \%$. Later the inverse creep strain of value $e_{11}^{c} \approx 0,019 \% \quad\left(e_{11}^{c} \approx 0,9 e_{11}^{e}\right) \quad$ was observed after $t_{1}=700 \mathrm{~h}$.

The analysis for straining process of the specimen using the model of nonstationary creep was performed with 35 steel material parameters shown in Table 1. 
The test results and their comparison with the obtained numerical data are shown in Fig. 2, which shows the creep curve (the solid line indicates the numerical results obtained by authors, and the markers indicate the corresponding experimental data). Qualitative and quantitative coincidence of experimental and calculated data observed.

Table 1. Physico-mechanical characteristics and parameters of the nonstationary creep model for steel 35 and ATV

\begin{tabular}{|c|c|c|}
\hline & $\begin{array}{c}\text { Steel 35 at } \\
T=450^{\circ} C\end{array}$ & $\begin{array}{c}\text { Steel ATV at } \\
T=538^{\circ} C\end{array}$ \\
\hline$K, \mathrm{MPa}$ & 128400 & 128400 \\
\hline$G, \mathrm{MPa}$ & 59270 & 59270 \\
\hline $\bar{C}_{c}^{(+)}, \mathrm{MPa}$ & 15 & 70 \\
\hline $\bar{C}_{c}^{(-)}, \mathrm{MPa}$ & 1,1 & 11,6 \\
\hline$g_{1}, \mathrm{MPa}$ & 2800 & 5000 \\
\hline$g_{2}$ & 100 & 200 \\
\hline$\lambda_{c}^{(0)},(\mathrm{MPa} \cdot \mathrm{h})^{-1}$ & $4,13 \cdot 10^{-8}$ & $7 \cdot 10^{-8}$ \\
\hline$\lambda_{c}^{(1)},(\mathrm{MPa} \cdot \mathrm{h})^{-1}$ & $4,13 \cdot 10^{-8}$ & $7 \cdot 10^{-8}$ \\
\hline$\lambda_{c}^{(-)},(\mathrm{MPa} \cdot \mathrm{h})^{-1}$ & $1 \cdot 10^{-5}$ & $6 \cdot 10^{-6}$ \\
\hline
\end{tabular}

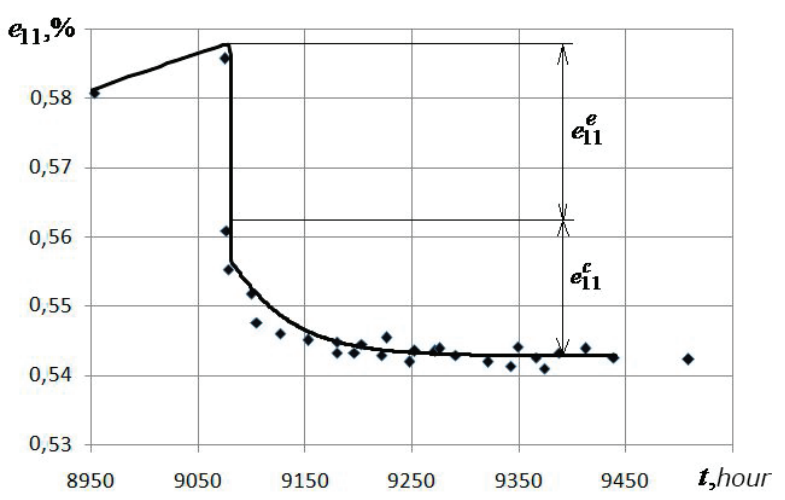

Fig. 2. Reverse creep curve of 35 steel at the temperature $T=450^{\circ} \mathrm{C}$

In the next example the steel ATV specimen was tested at the temperature $T=538^{\circ} \mathrm{C}$ and stress $\sigma_{11}=138 \mathrm{MPa}$ within $t=8060 \mathrm{~h}$. After that the specimen was quickly unloaded to the value $\sigma_{11}=7,7 \mathrm{MPa}$, elastic strain decreased to $e_{11}=0,0921 \%$. Later the inverse creep strain of value $e_{11}^{c} \approx 0,08 \%$ was observed after $t_{1}=2100 \mathrm{~h}$. ( $e_{11}^{c} \approx 0,9 e_{11}^{e}$ the same with previous example).

The analysis of the straining process of specimen using the model of nonstationary creep was performed with ATV steel material parameters shown in Table 1.

The test results and their comparison with the obtained numerical data are shown in Fig. 3, which shows the creep curve (the solid line indicates the numerical results obtained by authors, and the markers indicate the corresponding experimental data). Qualitative and quantitative coincidence of experimental and calculated data observed here as well.

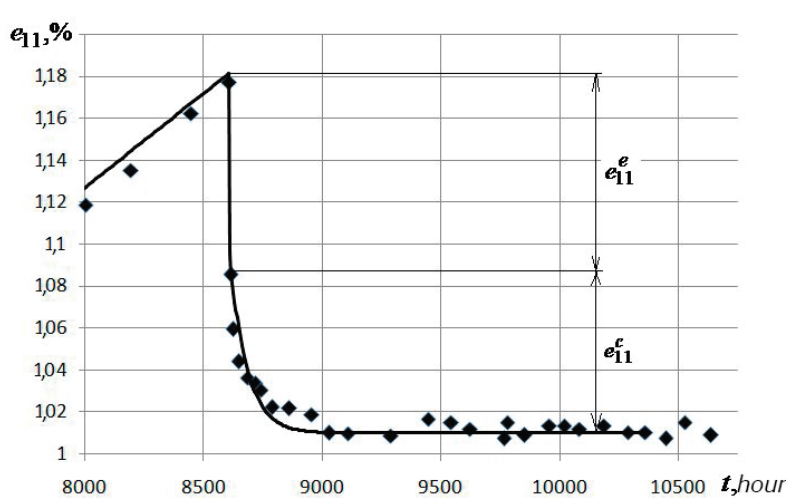

Fig. 3. Reverse creep curve of ATV steel at the temperature $T=538^{\circ} \mathrm{C}$.

\section{Conclusions}

A mathematical model describing the processes of nonstationary creep of structural materials (metals and their alloys) under complex loading is developed.

The results of numerical simulation and experimental data of reverse creep processes of structural steels are compared. It is shown that the developed variant of the defining relations of nonstationary creep allows to describe the processes of reverse creep of metals with required for engineering calculations accuracy.

The research was supported by the Russian Science Foundation, grant No.16-19-10237.

\section{References}

1. A.M. Lokoshchenko, Polzuchest' $i$ ditel'naia prochnost' metallov (Fizmatlit, Moscow, 2016) [in Russian]

2. I.A. Volkov, L.A. Igumnov, Yu.G. Korotkih, D.A. Kazakov, A.A. Emel'yanov, I.S. Tarasov, M.A. Guseva, Problemy prochnosti i plastichnosti, 78, №2, 188-207 (2016) [in Russian]

3. A.G. Kazancev, Problemy prochnosti, №5, 25-31 (1985) [in Russian]

4. Yu. N. Rabotnov, Polzuchest' ehlementov konstrukcij, (Nauka, Moscow, 1966) [in Russian]

5. D.A. Gohfel'd, O.S. Sadakov, Plastichnost' $i$ polzuchest' ehlementov konstrukcij pri povtornyh nagruzheniyah (Mashinostroenie, Moscow, 1984) [in Russian]

6. V.P. Degtyarev, Plastichnost' $i$ polzuchest' mashinostroitel'nyh konstrukcij. (Mashinostroenie, Moscow, Mashinostroenie, 1967) [in Russian]

7. N.N. Malinin, Prikladnaya teoriya plastichnosti $i$ polzuchesti. (Mashinostroenie, Moscow, 1968) [in Russian]

8. A.M. Lokoshchenko, Polzuchest' $i$ dlitel'naya prochnost' metallov (Fizmatlit, Moscow, 2016) [in Russian]

9. Dzh. Bojl, Dzh. Spens, Analiz napryazhenij pri polzuchesti. (Mir, Moscow, 1986) [in Russian] 
10. Ohasi Ono Kavai, Teoreticheskie osnovy inzhenernyh raschetov, ASME, 104, №3, 1-8 (1982) [in Russian]

11. A. Miller, Teoreticheskie osnovy inzhenernyh raschetov, ASME, №2, 1-20 (1976) [in Russian]

12. Yu. N. Shevchenko, R.G. Terekhov, Fizicheskie uravneniya termovyazkoplastichnosti, (Naukova Dumka, Kiev, 1982) [in Russian]

13. P. Pezhina, Osnovnye voprosy vyazkoplastichnosti, (Mir, Moscow, 1968) [in Russian]

14. J.L. Chaboche, Inter. J. of Plasticity, 5, No. 3, 247302 (1989) [in Russian]

15. N.N. Malinin, G.M. Khadjinsky, Inter. J. of Mechanical Science, 14, 235-246 (1972) [in Russian]

16. R.D. Krieg, J.C. Swearengen, R.W. Rohde, $A$ physically-based internal variable model for ratedependent plasticity. Inelastic behavior of pressure vessel and piping components ASME/CSME, PVPPB-028, 15-28 (1978) [in Russian]

17. I.A. Volkov, Yu.G. Korotkikh, Uravneniia sostoianiia viazkouprugoplasticheskikh sred s povrezhdeniiami (Fizmalit, Moscow, 2008) [in Russian]

18. I.A. Volkov, L.A. Igumnov, Iu.G. Korotkikh, Prikladnaia teoriia viazkoplastichnosti (UNN, Nizhny Novgorod, 2015) [in Russian]

19. I.A. Volkov, L.A. Igumnov, D.A. Kazakov, D.N. Shishulin, I.V. Smetanin, Problems of strength and plasticity, 78, 436 (2016)

20. A. Nadai, Plastichnost' $i$ razrushenie tverdykh tel (Izd-vo inost. lit., Moscow, 1969) [in Russian] 